This is a pre-copyedited, author-produced PDF of a journal article accepted for publication in Photography \& Culture journal, following peer review.

The published version:

Annebella Pollen, 'Sweet Nothings: Suggestive Brighton Postcard Inscriptions'

Photography and Culture, Volume 2, Number 1, March 2009, pp. 77-88

can be found here:

http://www.ingentaconnect.com/content/bloomsbury/pgcj/2009/00000002/00000001/ art00005

DOI: http://dx.doi.org/10.2752/175145209X419408

\title{
Sweet Nothings: Suggestive Brighton postcard inscriptions
}

\section{Annebella Pollen}

\begin{abstract}
This paper details the results of a research project searching for evidence of courtship in Brighton Museum's holdings of mainly topographical early twentieth century postcards. Assembling a body of evidence that demonstrates Brighton as a historic location for romance and the postcard as a flirtatious form of communication, 'Sweet Nothings' argues that while postcard inscriptions have been largely overlooked in academic literature, the coded and truncated messages intended to covertly express intimate exchanges in a public medium provide a suggestive means of understanding mass-produced postcards through their private singularisation and use.
\end{abstract}

\section{Keywords:}

Brighton - postcards - museums - public - private - inscription - romance - flirtation

\section{Introduction}

This research forms part of a six month post held at Brighton and Hove Museums in 2007 for a project entitled The Rules of Attraction. Supported by Museums, Libraries and Archives Council funding, six local residents from a range of backgrounds were employed as 'Researcher-Interpreters' to tell the 'hidden histories' of objects in the museums' collections through the theme of courtship. An exhibition of the team's work, 
ranging from short films to songs, was shown as On the Pull, Brighton Museum and Art Gallery, 2008.

\section{Behind the scenes}

Brighton museum's postcard holdings, although not yet fully catalogued or audited, are believed to be in excess of ten thousand. (1) Despite their large number, their range is narrow, for the vast majority are local photographic views. Most of the collection is preWorld War Two, and within this period, many are pre-World War One. The Edwardian era, when picture postcards were novel, cheap, collectable and, above all, functional in a period of unparalleled postal reliability has often been claimed as a 'golden age'.-Their popularity at that time is evidenced by their strong presence in the collection. Stored in safes, card index files and old shoe boxes marked 'Miscellaneous', the museum's postcards are currently dissipated across the collections of which they are part, rather than forming an autonomous category. While a significant number originate from the personal correspondence of residents or associates of the local Edwardian town house, Preston Manor, the majority of postcards, now housed in the Local History Centre, have been collected for and classified in terms of the locations their pictorial side records.

The segregation of postcards by place name is indicative of a classification system that privileges the pictorial image over the written content. That the topographical photography of the postcard's image is considered to be the principal significance of the postcards is underlined by their storage. Many have been individually wrapped in plastic bags with only one transparent side, evidencing the message side to be the historically inferior face. Catalogue numbers, museum stamps and stickers are applied only to the written side of the card, often in blatant contempt of the inscription, which is always damaged to a degree, and sometimes substantially or wholly obscured by this action. Some cards have their reverse entirely covered by blank stickers or by scribbled black ink or paint, as if the content of the message might undermine the integrity of the image-bearing surface. There is a temptation, given the focus of the Rules of Attraction 
research, to assume that what was censored was red-hot exchange, but it is probably more the case that the collectors who originally acquired and later donated the cards were following the market's lead, where cards that have been 'postally used' are diminished in value. (Phillips, 2000: 26) Many of the museum's older storage approaches appear to follow this bias and thus follow traditional image-based rather than objectbased curatorial treatment of photographic material (Edwards and Hart, 2004: 59).

\section{Two sides to the story}

In the vast literature on postcards - ranging from coffee-table books to serious historical overviews, from collector's valuation guides to publications that use cards to illustrate wider histories - the reverse rarely receives substantial consideration. David Vincent has observed, "Because of their role as a photographic record of a vanishing world they have been collected for their unwritten side. Historians have yet to turn them over". (Vincent, 2006: 381-2) Messages on postcards, it seems, are regularly ignored and dismissed for their apparent inconsequentiality and also for their troublesome ability to distract from, or even antagonise, the face-value reading of the images. Picturesque views and photographs of civic monuments seem to tell so much more straightforward a story than the frequently mystifying fragments of highly personal and decontextualised correspondence, yet it is the back of an inscribed and sent postcard that articulates the image's meaning through use, enabling a multifaceted reading of the photograph as a "socially salient object" (Edwards and Hart, 2004: 2).

It is worth noting that at the start of the picture postcard's career, the hierarchy between the front and the back had a rather different focus, for the written side was originally considered 'the front' of the postcard, and the image, 'the back'. While postcards emerged as purely textual devices in the 1860s - literally addressed and inscribed pieces of card - and then began to achieve their enormous popularity by the 1880 s, it was the introduction of the pictorial card around the turn of the century and, most significantly, the innovation of the divided back in 1904 - enabling the address and 
a message to be on the same side - that led to the progressive dominance in value of the postcard's image over its inscription. As Nancy Schor puts it, "With the division of the card's back the relationship between the two sides of the card was transformed ... the recto became the verso". Schor believes that the "gradual promotion of the iconic face of the illustrated postcard to primacy can be considered a sign of the rise of the culture of the image" (Schor, 1992: 212-3). The message side, whose very function brought the postcard into being, could thus not compete and became relegated to a kind of ' $\mathrm{B}$ ' side. In many of the postcards that form my research resource, however, the written side was still considered to be the front. In the detail of the printing on many picture postcards up to the mid-twentieth century, it is stated: "This space, as well as the back, may be used for communication."

Rather than set up an artificial 'either/or' competition between the postcard's two opposing sides, it is preferable to consider the postcard as a double-sided medium with two intersecting opportunities for meaning. Schor has claimed that this is the postcard's special significance; that "it is the perfectly reversible semiotic object, a virtual analogon of the sign". (Schor, 1992: 34) The scriptural side reanimates the image side in sometimes unexpected ways. As Frederic Vitoux has it, the relationship between the two sides of a postcard is "never gratuitous, even if it sometimes remains ambiguous." (Vitoux, 1973: 34)

\section{Repetition and variation: promiscuous messages}

Many of the most productive publications that appreciate and explore postcard inscriptions are non-academic in their approach, such as artist and collector Tom Phillips' millennium tome The Postcard Century: 2000 Postcards and their Messages (Thames and Hudson, 2000). This text, as the title suggests, includes messages as well as images, at least in transcript, for Phillips, unusually for a 'deltiologist', only collects inscribed and sent postcards, those, as he puts it, that have "lost their virginity" (Phillips, 2000: 16). Another work that closely engages with the postcard's message is Georges 
Perec's 1977 poem, "Two Hundred and Forty-Three Postcards in Real Colour", which mimics the repetitive tropes of the postcard message with variations on a prescribed theme. The obligatory mentions of the holiday location, weather and food are repeated and reorganised with subtle differences to highlight the flexible regulations of an overlooked literary genre. A random extract reveals the patterning:

A brief line from Tahiti. Lazing about and playing the ukulele. Paradise! I go riding. Friendly regards.

A brief line from Roscoff. Weather good. We eat very well. We've made some friends. Home on the $26^{\text {th }}$.

We've found a room at the Hotel des Fleurs. Weather good. We go to the beach. You should see my sunburn! Many regards. (Perec, 1999: 236)

The fundamental moral of this witty exercise in style is a pessimistic one: that the postcard's inscription consists of a finite set of possibilities limited by a narrow formula. While it is true that the lack of space on a postcard and its expected function - especially latterly, as conveyor of holiday greetings - can constrain much of the potential for expressive communication, to dismiss them on these grounds is to miss the variations on the theme that disclose so much by their writers' simple aberrations from the expected. While many postcards were used to impart factual information such as time of arrival or acknowledgement of receipt, the evidence that many suggest larger, deeper or more intimate detail shows not only the endless variety and creativity of the senders, but also the capacity of the postcard to express more than might be expected of its most humble and ephemeral conditions.

\section{Sweet nothings}


The wide availability of postcards, their long-standing popularity and their functional capacity inevitably make their visual and scriptural subjects heterogeneous. From polite greetings to enquiries after mislaid scissors, from pre-printed advertising cards to holiday souvenirs, the variety of individual sources - largely unknown and unknowable that have come together to form the disparate collection of Brighton Museum postcards mean that a variety of messages, images, purposes and meanings coexist. The postcards I have selected from the inscribed minority of the holdings represent only one angle that might be excavated. In pursuit of evidence of love / sex / attraction / dating / courting for the Rules of Attraction research brief, I looked at thousands of postcards with a onetrack mind, voyeuristically seeking any mention, explicit or covert, of desire. Even postcards probably innocent of intimate reference became suggestive with double entendre. This positive selection of messages of love and longing sourced from the museum's cards represents a personal selection and a reading based not on statistical representativeness, but on guided choices. I include this proviso not to diminish the presence of the 'longing' and 'loving' cards, but to contextualise them. Not every postcard from Brighton declares passion, but passionate cards most definitely exist, and in force.

How can such humble, cheap and prosaic rectangles of card stake a claim to complex, intimate emotions? Phillips has described the postcards' specific place in the history of intimate personal relationships: "Before the telephone comprehensively took over the territory," he notes, "courtship was the natural province of the postcard. What is now breathed down a phone, left on machines or emailed, had for half a century to be committed to the card". (Phillips, 2000: 13) The postcards I found act as wishes, testimonials and material manifestations of feelings shared or hoped for, whether scribbled in mauve indelible pencil or the more fugitive lead, or elegantly composed in often misspelled but beautifully-inked copperplate, and their spontaneous and intimate nature creates a palpable sense of proximity. In the postcards, small stories inhabit small spaces but are not contained by them, as the leaky medium allows intimate details 
of courtship performance to edge into the public domain. The postcard is a small thing, but is nevertheless capable of expressing big issues. The single, brief utterance can suggest so much more. The small talk of postcards may be likened to the sighs and gasps of 'pillow talk', or intimate exchanges where fully formed sentences are less likely to be found than 'sweet nothings'. As Roland Barthes has observed, the fundamental message of the love letter is, "I have nothing to tell you, save that it is to you that I tell this nothing." (Barthes, 1990: 157)

\section{Thinking of you at Brighton}

Brighton has long had a reputation as being a place for escape and romance, from its early development as a fashionable Regency site of pleasure and healing through to its associations with the 'dirty weekend'. The geographical location of Brighton as 'a place on the margin', a 'liminal zone' on the shoreline "betwixt and between" social codes, distinct from the normative practices of the everyday worlds of work, has, Rob Shields argues, enabled the town to become a space for "lapses in normal behaviour". (Shields, 1992: 108) It is true that Brighton as a place for love, or perhaps merely flirtation, is repetitively mentioned in inscriptions on the back of postcards, and it is noticeable that messages from Brighton indicate romantic themes that other places do not inspire. The frequency of the courtship theme in the Brighton postcards (as opposed to the paucity in the museum's 'Sussex' classification) helps substantiate Shields' assertion of seaside towns' particular propensity to sexual freedom. Whether these references to Brighton as a place encouraging licence are oblique, many of the cards connote pleasurable times had, from 1917's: “Dear Edie, We are all enjoying ourselves. You would like it here very much - plenty of soldiers..." to: "Dear Alice, What a ripping time we are having and scorching weather. I have a few titbits to tell you when I return. Ada and I have been paddling, showing all we have got..." (1907) 
Image 1

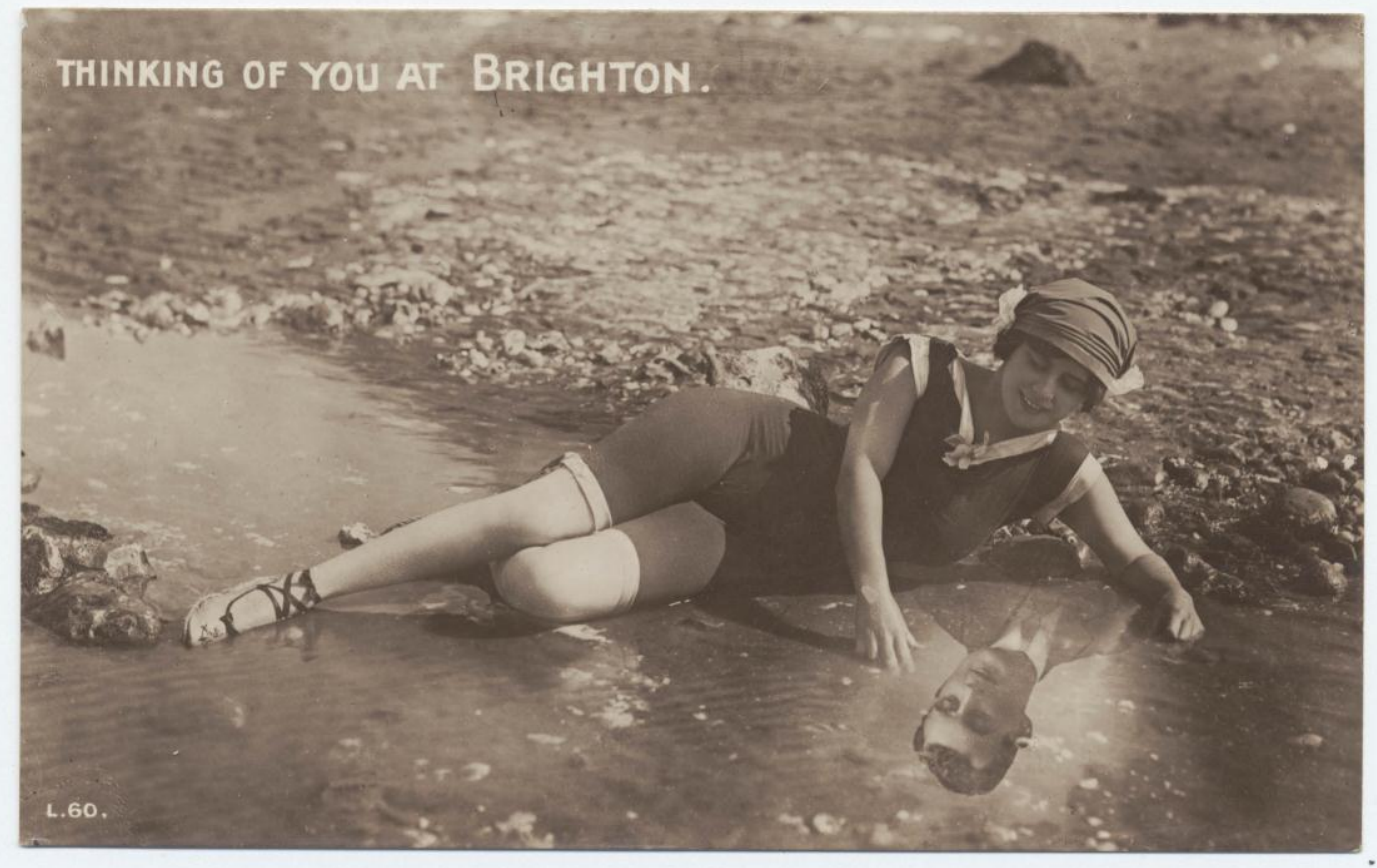


Image 2

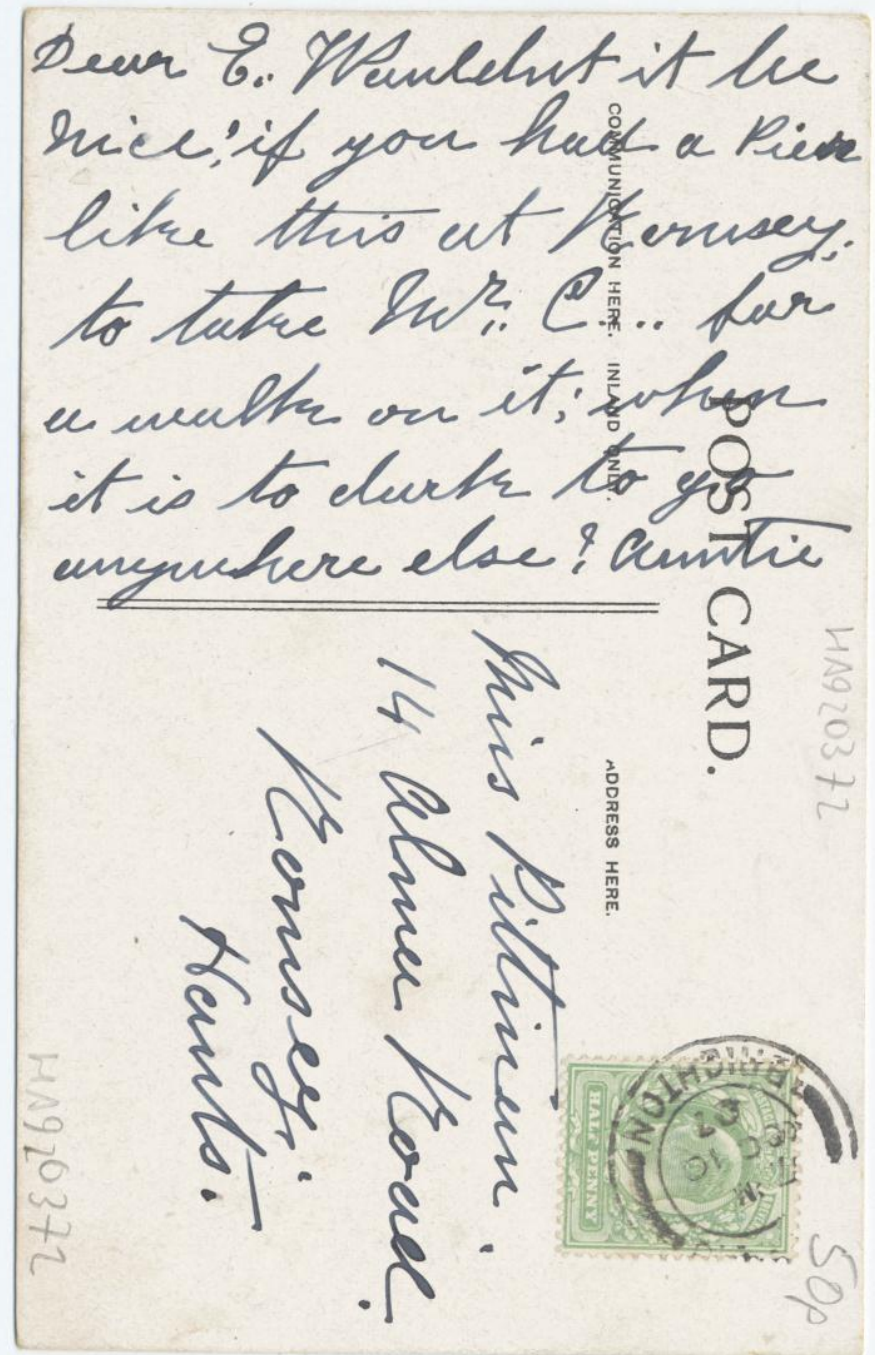

Caption: "Thinking of You at Brighton": Two sides of a 1907 card to Miss Pittinum from her auntie PHOTOGRAPH REPRODUCED WITH THE KIND PERMISSION OF THE ROYAL PAVILION \& MUSEUMS (BRIGHTON \& HOVE) 
While the majority of the cards in the Brighton Museum have been collected for their geographic imagery, by reading the postcard inscriptions the collection can generate a sited picture of where local romance could be found in the past. First and most literal of these locations is Lover's Walk in Preston Park. Perhaps referencing its pretty and dense foliage, 'N. V.' tells Miss Frossel in a postcard from 1904: "This is not like the one we know of but it looks a nice place for that sort of thing". Brighton's piers are other sites that have long been enshrined as mating places, and numerous postcards testify to this. Miss Pittinum's auntie wrote in 1907 on the back of a charming "Thinking of You at Brighton" card - one of the few non-view cards that have found their way into the museum's postcard collection - "Wouldn't it be nice if you had a pier like this at Romsey; to take Mr. C... for a walk on it; when it is to dark to go anywhere else?" [Image 1 and 2, front and back] In an intriguing card from "(darling) Beatie", the romantic possibilities of the pier and St. Anne's Well Pleasure Gardens are referenced. Beatie writes over the image on the postcard front as well as the back as she has so much news to share. [Image 3] She breathlessly refers to meetings with several different men in Brighton, including photographer Fred - "the sweet creature" - whom she confesses that she has not seen recently "as, you see, I have other fishes to fry". She adds, "I went on the Pier with Nurse Sunday we has a fine time, she introduced me to another Frank that fated name..." Beatie squeezes two Franks and a Fred onto the space on the balloon and the gap underneath, and promises to write a letter soon. Many postcard inscriptions are as suggestive as the first line of a novel. We can only imagine what the letter contained, unhindered by a lack of space and the decorum required of the publicly readable card. 
Image 3

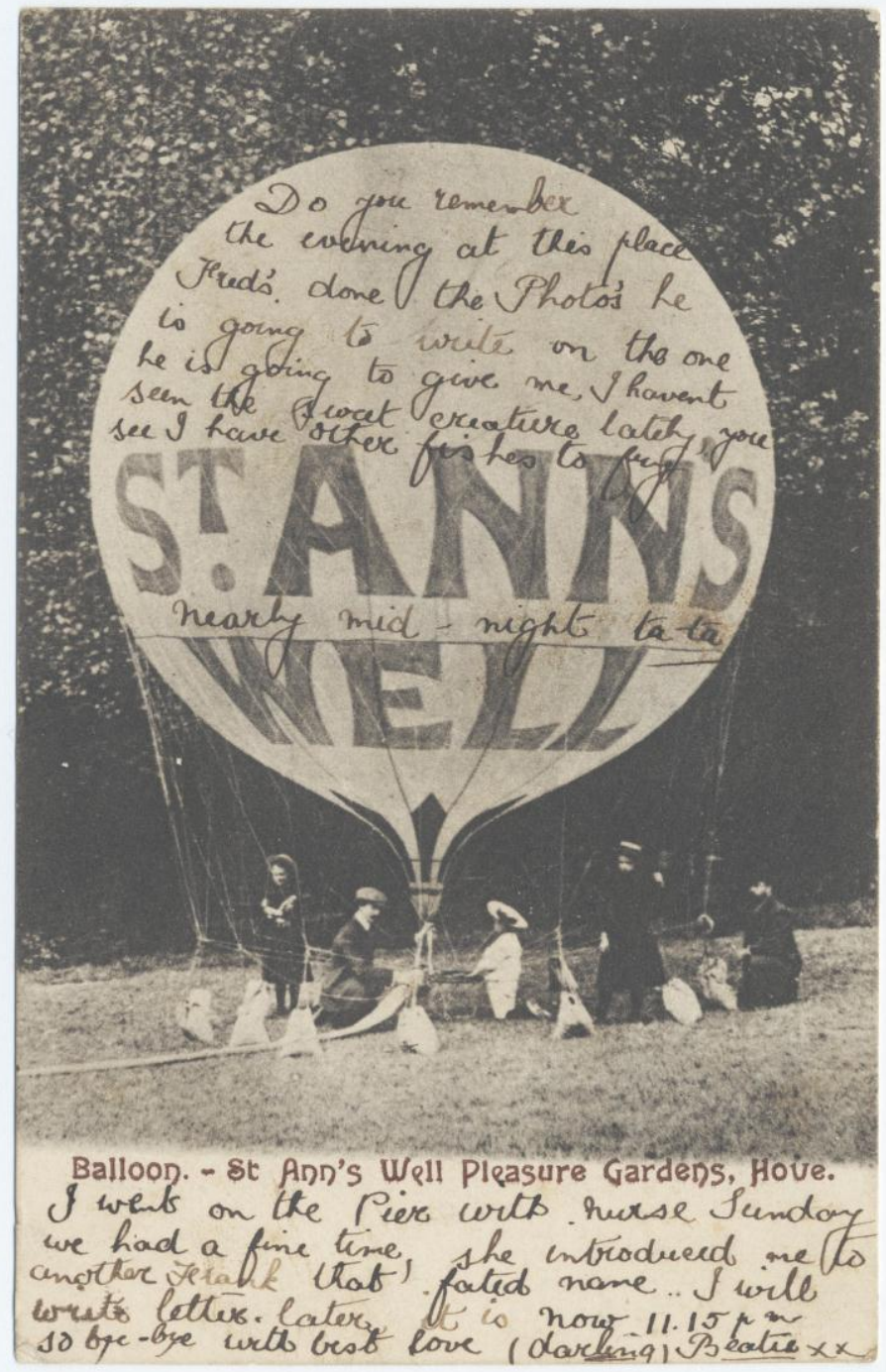

Caption: Midnight messages to “Dorry (Peach)" from “(darling) Beattie”, 1905

PHOTOGRAPH REPRODUCED WITH THE KIND PERMISSION OF THE ROYAL PAVILION \& MUSEUMS (BRIGHTON \& HOVE) 


\section{Naked notes}

Without an envelope, the postcard's exposed inscription seemed to suggest an inherent lack of discretion. London journalist James Douglas, writing in 1907, described the postcard as "a very curt and unceremonial missive" that "carries rudeness to the fullest extremity. There is no room for anything polite." (quoted in Staff, 1979: 79-80) Frank Staff has observed that "for many years the use of postcards was frowned upon by a certain class of person." (Staff, 1979: 47) It is worth remembering that until the midnineteenth century, letter writing was the privilege of the wealthy and educated. The cheap to buy and send postcard allowed for mass participation in the postal system, and enabled the newly literate to test out their skills. As Vincent has observed, "These were likely to be the only forms of literary communication in which some writers ever engaged." (Vincent, 2006: 382) Fears that circulated about the new material forms changing the ways in which people communicated have clear parallels with current debates about appropriate spelling and abbreviation in contemporary fast and informal communication methods - the email and the text message.

One of the concerns about postcards was that lyricism and poetry would be sacrificed in the necessarily brief message. In an amusing 1907 poem "Tirade à la Carte", Katharine Perry draws particularly attention to the effect postcards might have on the literature of love:

Think you that the Brownings, Robert and Elizabeth,

Had they lived at the present day,

Would have written those letters, passionate, prolonged,

Laden with love, glittering with Greek,

Riotous with references culled from the classics,

Crowded with casuistry and laments for the languorous lost lap-dog? -

Nay, - but a picture-postal of Thames Embankment would say - very squeezed as to writing:-- 
"Dear E. - Finished 'Sordello.' Done up. Can't come until Monday. Aff'ly, Robert."

Her reply, in the lee of a hotel at Margate, scalloped with sea-foam, -

"That's tough, Bobby love, - but till death I'm y'rs, -Liza."

(Perry, 1907: 336)

Perry's concerns about the postcard's lack of serious, considered and finely wrought text are appropriate enough if edited and rehearsed language is what is treasured. Postcard messages, however, are different in their intention and character. Whereas the formally composed letter may show a detached and organised structure, the postcard shows loose, spontaneous, involved and fragmented qualities that are more characteristic of the spoken word than of writing. (Carter, 2004: 57-8) Almost always breathless and usually cramped and hurried, the messages on the reverse are delivered in the heat of the moment - perfect for passion - and always say too little - perfect for suggestion. Flippant and teasing, coded and terse, the messages on the back of the cheap and throwaway cards are the written equivalent of flirtation.

\section{Between you and me (and the postman)}

In order to avoid the attention of a larger-than-intended audience, many writers of intimate postcards constructed encoding strategies rather than double the half-penny postage by adding an envelope. The truncated writing in postcards, then, may be read as a means of maintaining secrecy rather than displaying evidence of the paucity of literary skills or sophisticated feelings in their senders. While brevity, to a greater or lesser degree, is evident in all of the Brighton Museum postcard messages, levels of encryption vary. While some lovers might be happy to send a pictorial card announcing "I Love You" backed with a straightforward expression of longing - "With much love from one who is still thinking of you xxxx" - others were more covert with their feelings. Devices range from the very common and naïve method of writing the message upside down in relation to the address, to techniques including acronym and euphemism, code and mirror writing. 
A particularly evocative example in the Brighton Museum collection reads, "Dear Sis, Would you please endsa em omesa oneyma i will ellt ouya owha i aveha pentsa all my theroa. Had a implysa ovelya veninge last ightna owha $r$ getting hon + isha amena is ertba an eha isha wfullya icena, fondest love from Isabella commonly called Mabs". Roughly translated, this card states, "Would you please send me some money / I will tell you how I have spent all my other. Had a simply lovely evening last night / how are you getting on / his name is bert and he is awfully nice". Despite the relative transparency to anyone with any determination to decipher its backslang, the author's simple code, backed with an equally deflecting image of a local church, provided enough cover to discuss in public the twin indiscretions of her romantic and financial profligacy.

Image 4

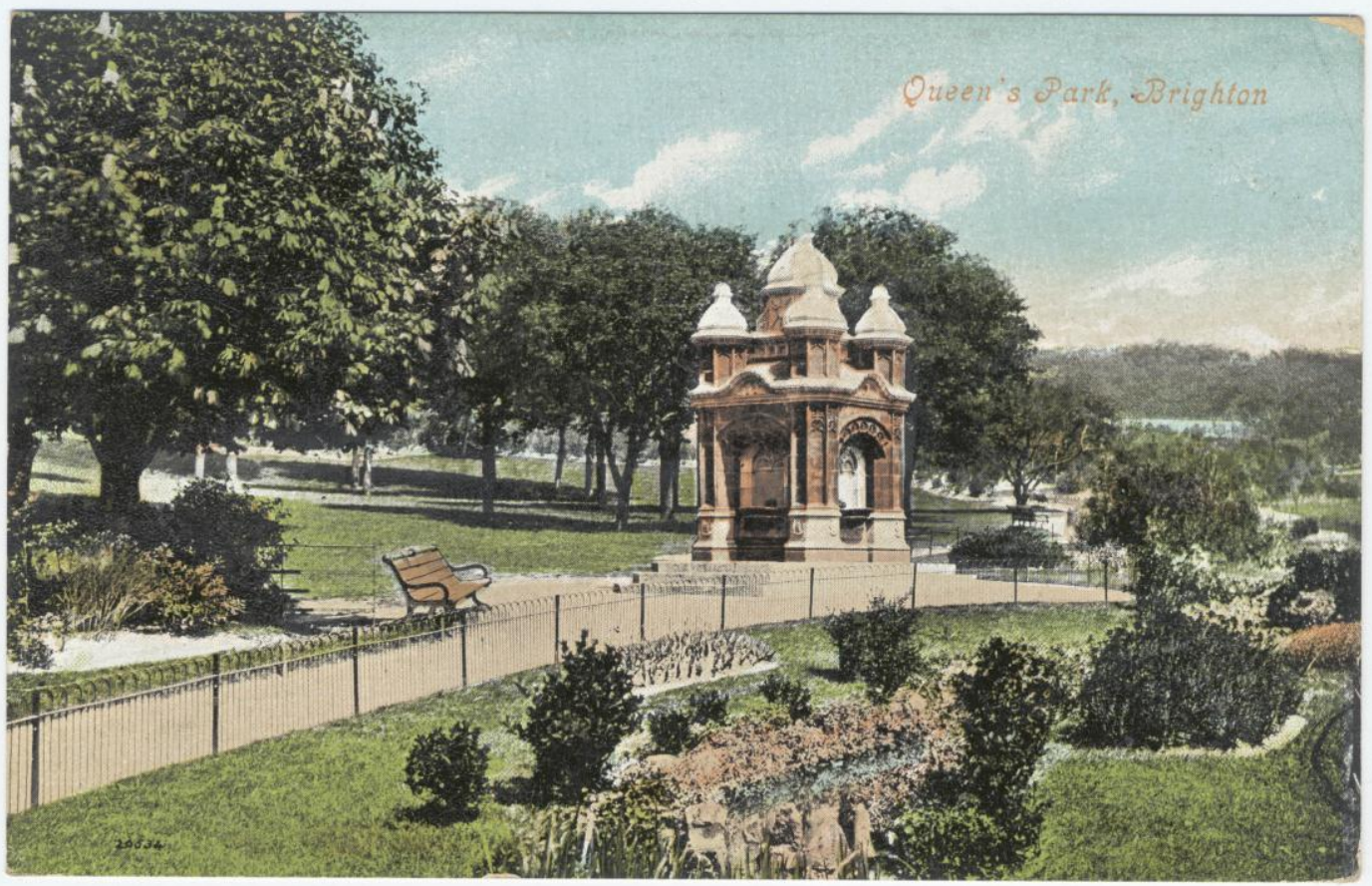


Image 5

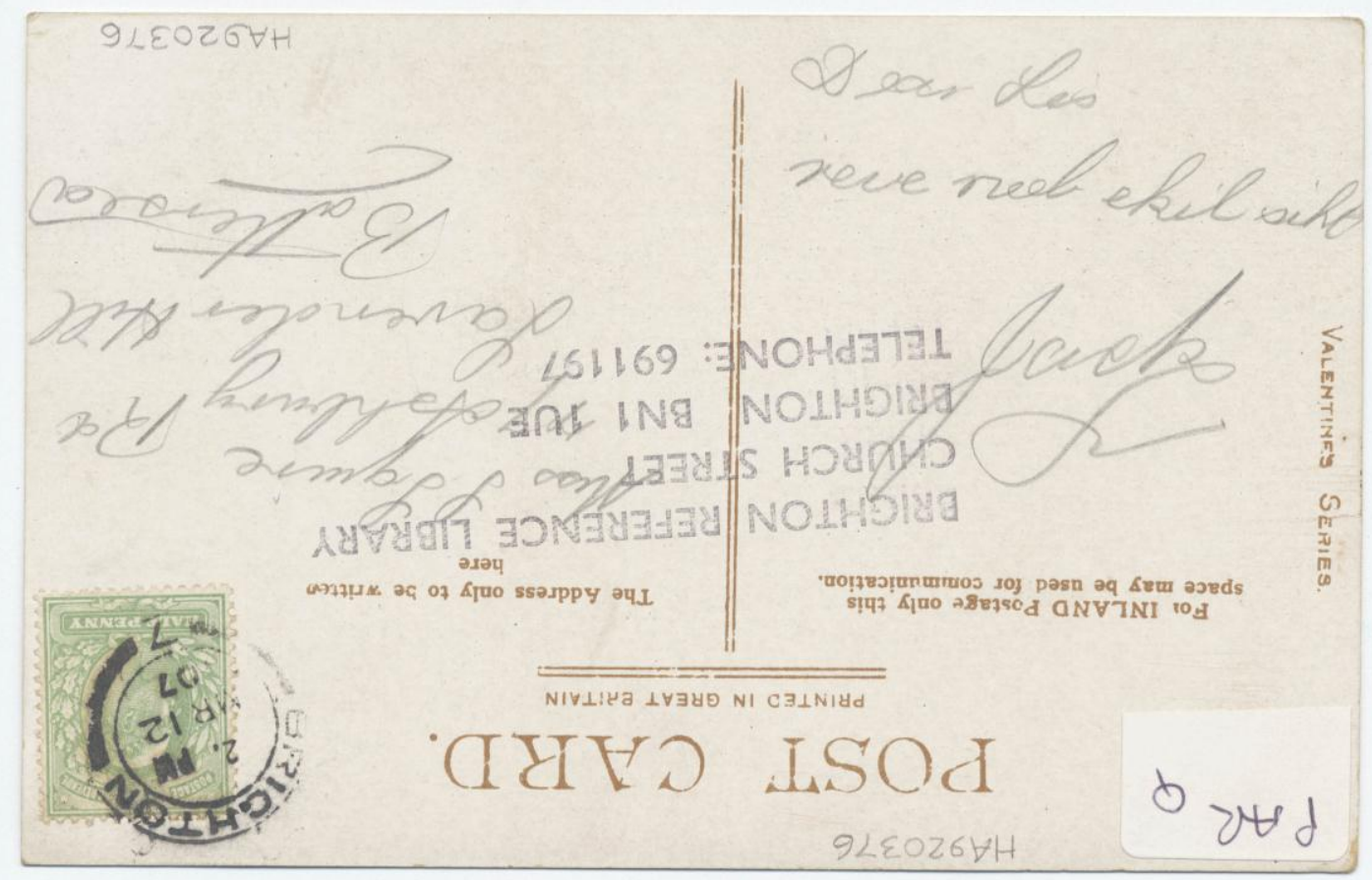

Caption: Feeling upside down and back to front: Jack's mirror writing to Les, 1907 PHOTOGRAPH REPRODUCED WITH THE KIND PERMISSION OF THE ROYAL PAVILION \& MUSEUMS (BRIGHTON \& HOVE)

In 1907, on the back of an unprepossessing view of Queen's Park, Jack asks Dear Les, "reve neeb ekil siht". [Image 4 and 5] Whether invoking being drunk, head over heels in love or simply in a spin, Jack's word inversion is the sum total of his message and exemplifies the postcard as a cheap, brief and spontaneous form of off-the-cuff communication. Jack is unusual amongst postcard correspondents represented by Brighton Museum, as he makes more than the usual single cameo appearance. On the back of a simply-coloured elevated view of Old Steyne, sent two years earlier to the same Miss L. Squire, he writes pithily, "I think you know this place". [Images 6 and 7] Jack and Les evidently utilised Brighton's pleasure gardens for the purpose that they were intended, and their correspondence inserts them firmly in the frame of the image. Mass-produced and roughly printed commercial photography of public sites of leisure 
are transformed by such inscriptions into singularised spaces of romantic assignation; private landmarks in long-lost love stories.

Image 6

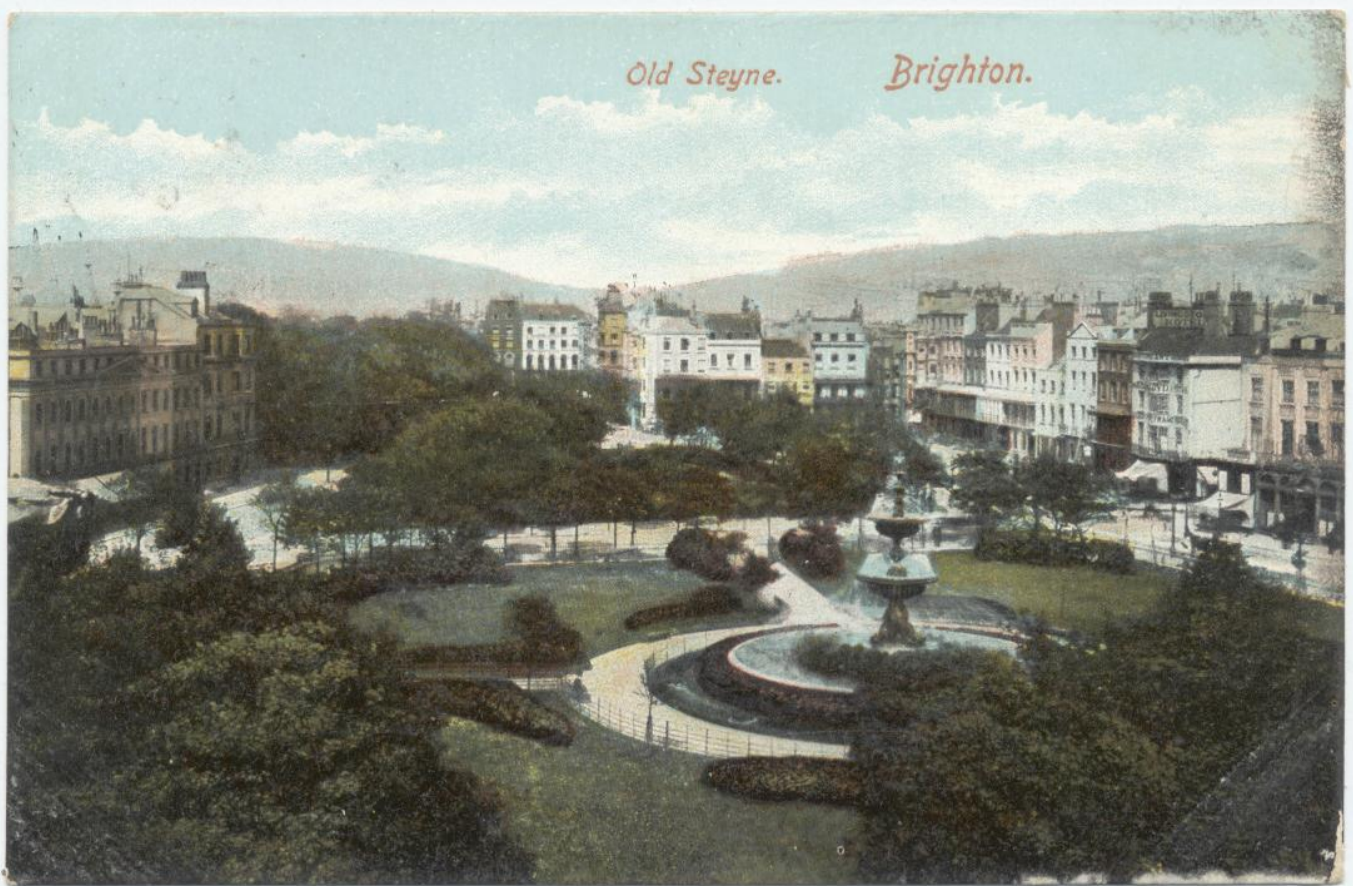


Image 7

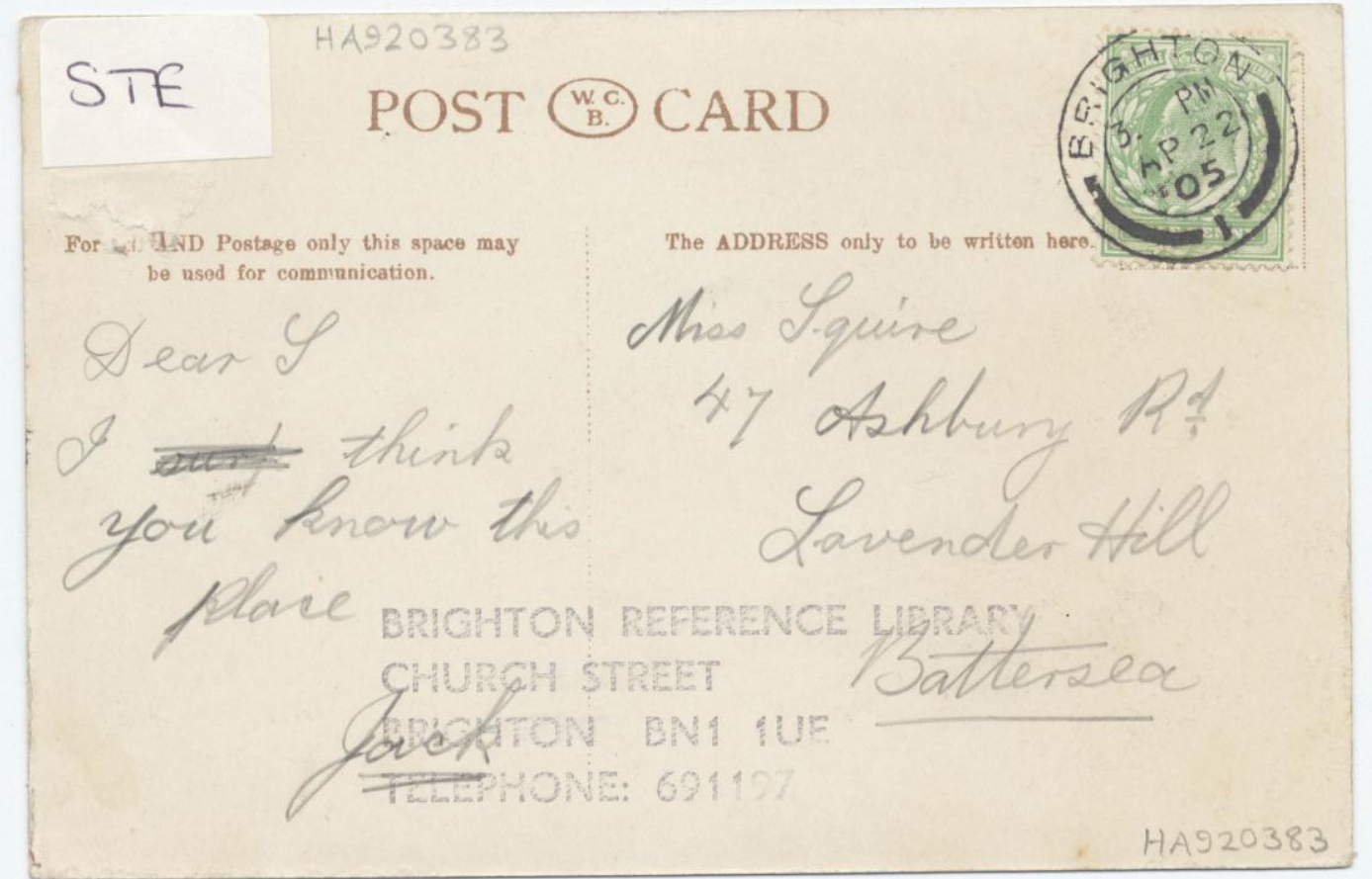

Caption: Commemorating Brighton's pleasure gardens: Jack to Les, 1905 PHOTOGRAPH REPRODUCED WITH THE KIND PERMISSION OF THE ROYAL PAVILION \& MUSEUMS (BRIGHTON \& HOVE)

Other methods used to conceal private messages were more literal. On an undated black and white postcard of Madeira Road, Burton's message begins innocuously. "Were any of your relations staying at Albion House Brighton" he asks, then announces on the reverse, "I have got some news for you but as I don't want anyone else to read it I will try and put it under the stamp." [Image 8] The message, like so many, was small but potent through its public / private peek-a-boo. The frustrating trace of the remaining message evokes a half-heard whisper, made all the more intriguing through the violence of the torn paper. 
Image 8

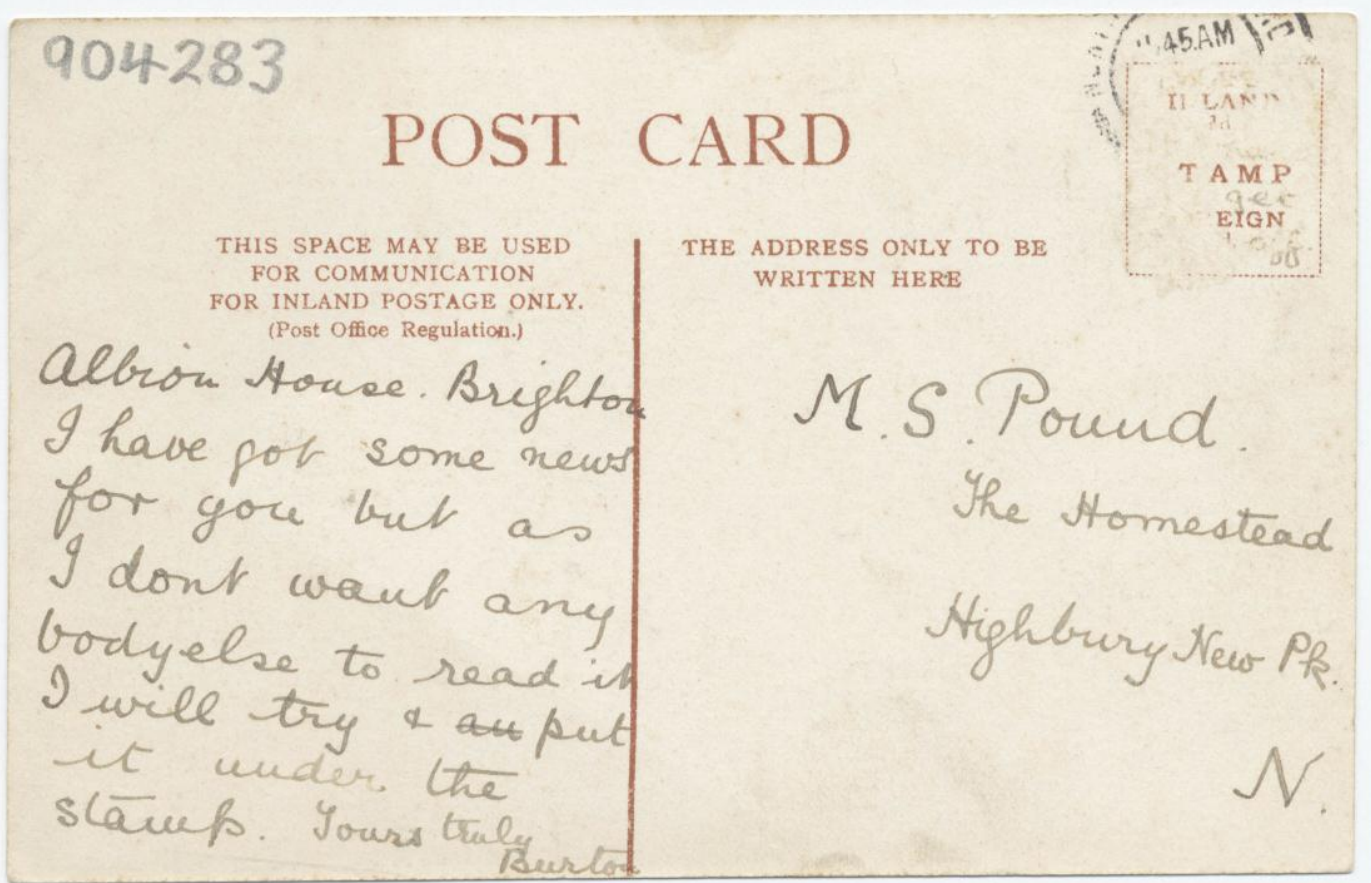

Caption: “I don't want anyone else to read it": Burton's secret, undated.

PHOTOGRAPH REPRODUCED WITH THE KIND PERMISSION OF THE ROYAL PAVILION \& MUSEUMS (BRIGHTON \& HOVE)

In Postcards: True Stories that Never Happened, a volume of graphic short stories inspired by postcard messages, collector Jason Rodriguez notes that he has several cards that use a similar method of concealment, sometimes with an ' $\mathrm{X}$ ' - a kiss - as the buried treasure. (Rodriguez, 2007: 80) If a sender was too shy or cautious to proclaim themselves in public, the stamp could act as wrapping paper for the gift, or as a veil for that which is too precious or forbidden to be seen. While an $X$ as a kiss appears in several instances in Brighton Museum postcards, it can also act as written intervention in the image. 
Image 9

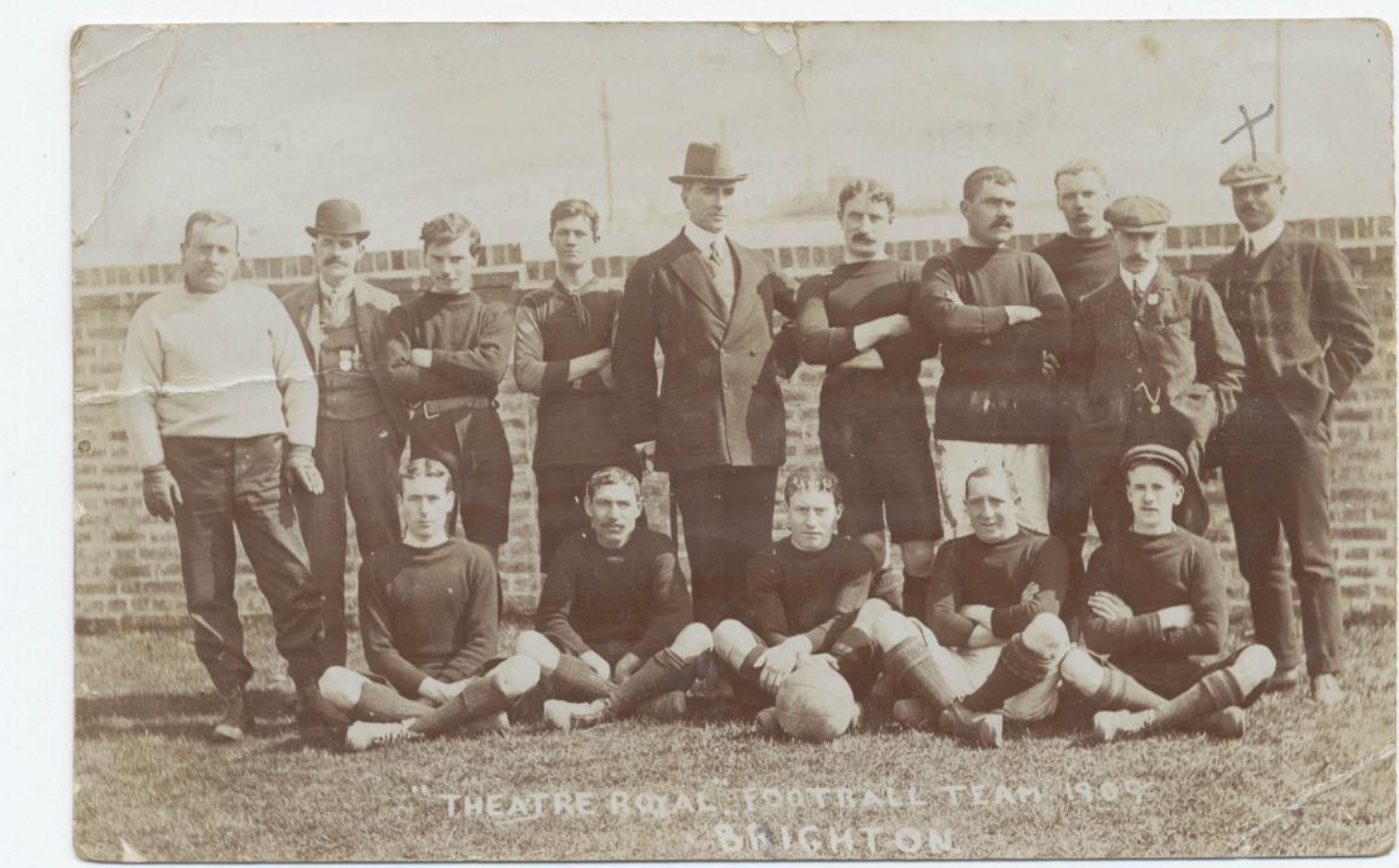

Caption: "The boy I told you about", 1909

PHOTOGRAPH REPRODUCED WITH THE KIND PERMISSION OF THE ROYAL PAVILION \& MUSEUMS (BRIGHTON \& HOVE)

"Dear Old Ede", writes Lou in 1909, "Am sending you [a] photo of the boy I told you about. What do you think of him?" [Image 9] With an X, Lou highlights her "boy' for her friend's consideration. In the age of 'Real Photo Postcards', where a wide range of popular subject matter could be produced in postcard form, a photograph as specific in subject as the Theatre Royal football team could be bought, sold and shared, annotated and scrutinized, not simply for art or sport, but also for love. An altogether more mysterious $\mathrm{X}$ appears on an undated postcard of the eastern end of Brighton seafront. Backed only with " $X$ mark the spot where my body lays at nights", the dramatic, poetic phrasing that may amount to no more than an announcement of the sender's accommodation becomes suggestive through its brevity. Without a stamp, postmark, 
address or name, the statement stands alone, weighted with significance. Simple sentences on postcards left hanging in history float freely, their inscrutability open to interpretation, their gaps and silences waiting to be filled.

\section{Postscript}

Such is the character of much postcard inscription: the few words become epigrammatic when isolated on the page, haiku-like in their capacity to reveal more than the sum of their parts. Sent in passing, written in code and whispered between two, the now preserved, deciphered and overheard intimate postcards offer multiple windows into the personal communications of the past, enabling access to first-person histories through their informality and immediacy. Their mass-production coexists with their private capacity to not only communicate tender feeling between lovers, but also to sustain and materialise it. To consider postcards solely in terms of their image denies their particular material qualities, and their cultural and historical significance. Just as a letter may be considered more than a means of communication, the written postcard also acts as a physical trace and a "token of the absent other" (Margaretta Jolly, 1997: 115). Postcards may be small, cheap and abundant but as inscribed carriers of emotional meaning they have the potential to become powerful and tangible material to be treasured, pressed to the lips or placed under a pillow. 


\section{Notes}

(1) Kevin Bacon, Curator of Photographs, Royal Pavilion \& Museums (Brighton \& Hove)

\section{Bibliography}

Barthes, Roland A Lover's Discourse: Fragments Translated by Richard Howard (London: Penguin, 1990)

Carter, Ronald Language \& Creativity: The art of Common Talk (London and New York: Routledge, 2004)

Edwards, Elizabeth and Janice Hart "Introduction: Photographs as Objects" in Elizabeth Edwards and Janice Hart (eds.) Photographs, Objects, Histories: On the Materiality of Images (London and New York: Routledge, 2004)

Edwards, Elizabeth and Janice Hart "Mixed Box: The cultural biography of a box of ethnographic photographs" in Elizabeth Edwards and Janice Hart (eds.) Photographs, Objects, Histories: On the Materiality of Images (London and New York: Routledge, 2004)

Jolly, Margaretta "Love Letters vs. Letters Carved in Stone: Gender, Memory and the Forces Sweethearts Exhibition" in Martin Evans and Ken Lunn (eds.) in War and Memory in the Twentieth Century (Oxford: Berg. 1997)

Perec, Georges "Two Hundred and Forty-three Postcards in Full Colour" Species of Spaces and Other Pieces (London: Penguin, 1999 (1974))

Perry, Katharine "Tirade à la Carte" Putnam's Monthly (Vol 3, no. 3, December 1907) Phillips, Tom The Postcard Century: 2000 Cards and their Messages (London: Thames and Hudson, 2000)

Rodriguez, Jason Postcards: True Stories that Never Happened (New York: Villard, 2007) Schor, Naomi "Cartes Postales: Representing Paris 1900" Critical Inquiry, Vol. 18, No. 2. (Winter, 1992), pp. 188-244.

Shields, Rob Places on the Margin: Alternative geographies of modernity (London and New York: Routledge, 1992)

Staff, Frank The Picture Postcard and its Origins (London: Lutterworth Press, 1979) 
Vincent, David "The Nineteenth Century Communication Revolution" in Maybin, Janet and Joan Swann The Art of English: Everyday Creativity (London: Palgrave Macmillan, 2006)

Vitoux, Frederic Cartes Postales (Paris 1973) 